\title{
THE SIGNIFICANCE OF QUANTITATIVE EVIDENCE IN FEDERAL TRADE COMMISSION DEGEPTIVE ADVERTISING CASES
}

\author{
DAVID W. BARNES*
}

I

\section{INTRODUCTION}

The Federal Trade Commission (FTC) has no guidelines for the development, presentation, and evaluation of statistical evidence by litigators or administrative law judges in deceptive advertising cases. ${ }^{1}$ As a result, Commission opinions and evidentiary findings related to statistical testimony run to hundreds of pages, discouraging the most determined reader, while orders emerging from the decisions are vague as to their implications for statistical proof of a "reasonable basis" for making an advertising claim. Statistical evidence is nothing new to the hearing examiners, who were considering quantitative arguments in both unfair competition $^{2}$ and unfair trade practice ${ }^{3}$ cases even before Title VII came into effect, ${ }^{4}$ which gave rise to the tremendous growth in quantitative analysis in employment discrimination law. The increasing sophistication of lawyers, who are growing accustomed to complex tools of statistical inference in discrimination cases, ${ }^{5}$ and changes in the law, particularly in the commercial speech area, suggests that an examination of the process by which litigators present and judges evaluate quantitative evidence is appropriate. ${ }^{6}$

The elevation of commercial speech to a constitutionally protected status

Copyright (C) 1983 by Law and Contemporary Problems

* Associate Professor of Law and Director, Center for Interdisciplinary Legal Studies, Syracuse University College of Law.

1. By comparison, the Food and Drug Administration at least indicates in its regulations what it considers to be methodologically sound statistical support for product claims. See infra text accompanying notes 13-18.

2. Diamond Alkali Co., 72 F.T.C. 700 (1967).

3. Stauffer Laboratories, Inc., 64 F.T.C. 629 (1974), affd, 343 F.2d 75 (9th Cir. 1965).

4. 42 U.S.C. $\S \S 2000$ e to 2000 e-17 (1976 \& Supp. V 1981).

5. Practitioners' handbooks devoted exclusively to the use of statistical proof in discrimination have appeared. See, e.g., D. Baldus \& J. Cole, Statistical Proof of Discrimination (1980); W. Connolly \& D. Peterson, Use of Statistics in Equal Employment Opportuntty litigation (1980).

6. Concerned litigators have inaugurated efforts to reform pretrial discovery and practice procedures in order to facilitate complex litigation. The association of the Bar of the City of New York, for instance, has appointed a Special Committee on Empirical Data in Legal Decision Making which has drafted Recom. mendations Conceming the Management of Complex Cases with Substantial Data. Special Committee on Empirical Data in Legal Decision-Making, Recommendations Concerning the Management of Complex Cases with Substantial Data (Draft, Oct. 7, 1982) [hereinafter cited as Data Committee Recommendations]. This draft follows the spirit of the evidentiary "protocols" suggested for use in administrative tribunals in $M$. Finkelstein, Quantitative Methods in LaW 232-47 (1978). 
might be interpreted as requiring that those seeking to enjoin commercial speech bear a heavy burden of proof in showing that it is misleading or deceptive to a substantial number of consumers in order to overcome the constitutional presumption in favor of its free flow. Commentators in the deceptive advertising area are undecided whether the decision in Virginia State Board of Pharmacy v. Virginia Citizens Consumer Council, Inc. ${ }^{7}$ constrains FTC decisionmaking authority under section 5 of the Federal Trade Commission Act, ${ }^{8}$ presumably because the FTC authority is directed specifically at that area of commercial speech, deceptive or misleading advertising, that the Supreme Court leaves open to state and, presumably, federal regulation. ${ }^{9}$ The Court recognized that "the greater objectivity and hardiness of commercial speech may make it less necessary to tolerate inaccurate statements for fear of silencing the speaker" 10 and that "[s]ince advertising is the sine qua non of commercial profits, there is little likelihood of its being chilled by proper regulation and foregone entirely."11

Restrictions on all speech, however, must serve a "substantial" governmental interest. ${ }^{12}$ Proper enforcement of restrictions on speech, designed to ensure that "the stream of commercial information flow[s] cleanly as well as freely," 13 might be construed as requiring a balancing of the constitutional interest in free speech against the governmental interest in truthful advertising in instances when a particular advertisement informs some consumers and misleads others. Even conceding that ensuring the clean flow of commercial speech promotes a substantial governmental interest and that the FTC regulations are no more extensive than necessary to serve that interest, an advertisement that is otherwise lawful must nevertheless be proved to be misleading before its constitutional protection is removed. ${ }^{14}$

To avoid casting off constitutional protection lightly, courts might require clear and convincing proof of the misleading character of speech before enjoining it. Concurring in Virginia Pharmacy, Justice Stewart suggested that the extension of constitutional protection to commercial speech "calls into immediate question the constitutional legitimacy of every state and federal law regulating false or deceptive advertising."15 The Third Circuit has echoed these sentiments stating: "[D]oubtless the Commission's broad construction of its $\S 5$ remedial authority

7. 425 U.S. $748(1976)$

8. 15 U.S.C. $\$ 45$ (1976 \& Supp. V 1981).

9. Virginia State Bd. of Pharmacy, 425 U.S. at 771-72; Warner-Lambert Co. v. FTC, 562 F.2d 749 (D.C. Cir. 1977), cert. denied, 435 U.S. 950 (1978). Relevant commentary includes: Knapp, Commercial Speech, the Federal Trade Commission, and the First Amendment, 9 MEM. ST. U.L. REV. 1 (1978); Westen, The First Amendment: Barrier or Impetus to FTC Advertising Remedies?, 46 BROOKLYN L. REV. 487 (1980); Note, Corrective Advertising and the Limits of Virginia Pharmacy, 32 STAN. L. REV. 121 (1979); Recent Development Note, First Amendment Restrictions on the FTC's Regulation of Advertising, 31 VAND. L. REV. 349 (1978).

10. Virginia State Bd. of Phamacy, 425 U.S. at 771-72 n.24.

11. Id.

12. Central Hudson Gas \& Elec. Corp. v. Public Serv. Comm'n, 447 U.S. 557, 566 (1980).

13. Virginia State Bd. of Pharmacy, 425 U.S. at 772.

14. The requirements that (1) commercial speech concern lawful activity and not be misleading, (2) the regulation serve a substantial governmental interest, and (3) the regulation be no more extensive than necessary were announced by the Supreme Court in Central Hudson Gas \& Elec. Corp. v. Public Serv. Comm'n, 447 U.S. 557, 566 (1980).

15. Virginia Stale Bd. of Pharmacy, 425 U.S. at 776 (Stewart, J., concurring). 
cannot survive the demise of the commercial speech exception to the first amendment."16

Greater clarity in the presentation, litigation, and evaluation of statistical evidence and greater specificity in remedial orders with respect to the requisite statistical bases for advertising claims are a logical part of the restructuring of deceptive advertising regulations. Even without this constitutional shadow upon restraints on speech by advertisers, the FTC, as a guardian of the competitive process, has an incentive to ensure that the public welfare is served by the flow of commercial information and that only demonstrably misleading messages are enjoined. In essence, the issue is: how demonstrably deceptive must a trade practice be before an injunction is appropriate, or, alternatively phrased so as to disclose the statistical and procedural issues, what kind of demonstration will suffice to justify an injunction and what process will best ensure that the statistics themselves are not misleading?

Sections II and III of this article consider a variety of guidelines that have been used or recommended to direct scientific and econometric research in several substantive law areas. Characteristics peculiar to the factual issues in deceptive advertising cases are highlighted and compared to issues arising in those areas. An examination of the distinction between and relevance of "practical significance" and "statistical significance" in Section IV leads to the identification in Section V of principles which would clarify and simplify both litigation and remedies in deceptive advertising.

\section{II}

\section{FDA Principles Provide a Model for Administrative Evaluation of Clinical Studies}

The Food and Drug Administration (FDA) has adopted a set of principles that provide the basis for determining whether there is "substantial evidence" to support effectiveness claims for drugs. ${ }^{17}$ These principles anticipate that there will be adjudicatory consideration of expert testimony based upon clinical investigations which demonstrate that the drug will have the effect it is represented to have. ${ }^{18}$ The principles are based on standards recognized by the scientific community as essential to an adequate and well-controlled clinical study. ${ }^{19}$ While the FTC has rejected this "adequate and well-controlled" standard in favor of a "reasonable basis' for making performance claims" standard ${ }^{20}$ the FDA guidelines do indicate what constitutes sound quantitative evidence. These indicia may be applicable to a number of cases over which the FTC exercises its deceptive advertising jurisdiction.

The FDA principles require that a reported effectiveness study include, inter alia:

\footnotetext{
16. Beneficial Corp. v. FTC, 542 F.2d 611, 620 (3d Cir. 1976), cert. denied, 430 U.S. 983 (1977).

17. 21 C.F.R. $\$ 314.111$ (a)(5)(ii)(a)-(c) (1983).

18. 21 C.F.R. $\$ 314.111$ (a)(5)(i) (1983).

19. Pfizer, Inc., 81 F.T.C. 23, 62 (1972).

20. Id.
} 
1. "A clear statement of the objectives of the study."

2. A method of selecting subjects for the study that assures suitability.

3. Unbiased treatment of subjects in their assignment to test and control groups.

4. Explanation of the "methods of observation and recording of results" and of the "steps taken to minimize bias on the part of the subject and observer."

5. A presentation of results in a manner that is amenable to quantitative analysis.

6. A summary of analytical methods including statistical methods and an evaluation of the data derived from the study. ${ }^{21}$

FDA procedural rules clearly indicate that any of these criteria may be waived by the Director of the Bureau of Drugs if a person who would be adversely affected by application of the principles petitions for such relief, demonstrates the nonapplicability of the principles, and indicates substitute alternative methods which will ensure the scientific integrity of the study. ${ }^{22}$ However, studies for which there is no control group or only a partial control group are not acceptable as the sole support for a performance claim, although they may serve as corroboration, and "[i]solated case reports, random experience, and reports lacking the details which permit scientific evaluation" are not to be considered at all. ${ }^{23}$

These principles are designed to provide enough background and evaluation material so that someone other than the researcher can (1) appreciate the nature and procedure of the study, (2) replicate it if that is desired, and (3) reanalyze the data. The first and third requirements are of particular importance to a finder-offact who must appreciate the purposes of and assumptions underlying a study in order to determine the relevance of the scientific inquiry to the legal issue at hand. The fact finder then must be able to reanalyze the data in order to fit the scientific conclusions into an appropriate legal context or procedural posture. The replication requirement serves as a guarantee of the investigator's experimental and evaluative abilities as well as his honesty since it provides for verification of the results.

The need to put scientific conclusions into a legal procedural framework and the difference between scientifically significant results and legally significant results are illustrated by Certified Color Manufacturers Association $v$. Mathews, ${ }^{24}$ a case in which finders-of-fact evaluated the safety of the food additive, Red Dye No. 2. Although this case arose under the Federal Food, Drug, and Cosmetic Act, ${ }^{25}$ it might easily have been a deceptive advertising claim before the FTC.

In Certified Color, Dr. Gaylor reported on a biostatistical study conducted specifically for the Toxicological Advisory Committee established by the Commissioner of Food and Drugs to make recommendations on the safety of Red Dye No. 2. He had found a statistically significant positive relationship between the dietary dosage of Red Dye No. 2 and the frequency of cancer in test rats. An ad hoc "Working Group," convened to review the study and apply the scientific evidence

21. 21 C.F.R. $\S 314.111$ (a)(5)(ii)(a)(1)-(5) (1983)

22. 21 C.F.R. $\$ 314.111$ (a) (1983).

23. 21 C.F.R. $\$ 314.111$ (a)(5)(ii)(c) (1983).

24. 543 F.2d 284 (D.C. Cir. 1976).

25. 5 U.S.C. $\S \S 701-706,21$ U.S.C. $\S 376$ (1976 \& Supp. V 1981 ). 
to the legal context in which the issue arose, came to six conclusions which present a picture of confusion as to the scientific implications of the study.

Two pieces of evidence supported a finding that Red Dye No. 2 was a carcinogen:

1. Female rats in the high dosage groups suffered a "statistically significant increase in malignant tumors" compared to those in the control group, and

2. There was a "possible" relationship between increased dose and increased likelihood of malignant tumors for females in all four dosage groups. ${ }^{26}$

Evidence not supporting carcinogenicity included four findings:

1. There was "no statistically significant increase in malignant tumors" demonstrated in male rats,

2. If one aggregated all types of tumors, there was no significant relationship between dose and likelihood of cancer,

3. No rats had any "unusual or unique" tumors, and

4. No single tumor type showed an increase over that observed in the control group. ${ }^{27}$

While this study led to scientific uncertainty as to the carcinogenic properties of Red Dye No. 2, it led to no legal ambiguities. This illustrates the important translation from scientific to legal significance. The Federal Food, Drug, and Cosmetic Act ${ }^{28}$ required that an additive be deemed unsafe unless the Commissioner, exercising his scientific judgment in determining whether safety had been proven, had issued a regulation indicating that the additive had been found suitable for general use or for particular specified uses. ${ }^{29}$ At the effective date of the Act many additives would have been "deemed unsafe" 30 automatically because investigations into their safety would not yet have occurred. Accordingly, some additives were given "provisional listings" 31 pending completion of appropriate scientific tests. For Red Dye No. 2, the scientific uncertainty resulting from Dr. Gaylor's study meant that the ongoing tests would not be able to prove that the additive was safe. Even though the study did not conclusively establish that the additive was unsafe, the completion of the study eliminated any justification for either the provisional listing or for postponing the removal of Red Dye No. 2 from the approved list. According to the court, "Cessat ratione, cessat' postponement."32 While popular reports at the time of this termination of listing suggested that the additive caused cancer, the legal significance of the study was that there was no immediate prospect of proving the additive to be safe. The legal significance

26. 543 F.2d at 291 n.35. The first of these findings compares cancer rates between those female rats receiving dietary concentrations of $3 \%$ Red Dye No. 2 to those receiving $0 \%$ Red Dye No. 2. The second finding considers the effect among four groups of rats, each of which was assigned a different dietary concentration of $0 \%, 0.003 \%, 0.3 \%$, or $3 \%$ Red Dye No. 2. Id. at 290 . The second finding thus allows the researcher to examine the effect of small increases in exposure to the carcinogen while the first allows a comparison between two groups.

27. Id. at 291 n.25.

28. 21 U.S.C. $\S \S 301-392$ (1976 \& Supp. V 1981).

29. Cerifized Color Mfrs. Ass'n, 543 F.2d at 287.

30. Id.

31. Id. at $286-87$.

32. Id. at 292. 
derives from an appreciation of the scientific method behind the study which enables one to interpret the results and their scientific significance.

Appreciation of a clinical investigator's method and assumptions is critical not only in nonadjudicatory proceedings, such as Certified Color, but also in adjudicatory hearings such as those conducted by the FTC in deceptive advertising cases. In ITT Continental Baking Co., ${ }^{33}$ the Wonder Bread case, the FTC ordered a manufacturer, seller, and distributor of bakery products to cease misrepresenting the nutritional content of its bread. ${ }^{34}$ Dr. Peter Rossi was one of the experts called by the manufacturer to testify on consumers' perceptions, derived from television advertisements, of Wonder Bread's nutritional qualities.

On direct examination, Dr. Rossi estimated that between $10 \%$ and $25 \%$ of the housewife population regarded Wonder Bread as nutritionally superior to other breads. ${ }^{35}$ Giving a range within which an expert expects an estimate to fall is a common method for statisticians to reveal their uncertainty regarding a particular conclusion.

The study on which this conclusion was based was actually two different studies concerning two different subjects. An analysis of the study on cross-examination revealed that Dr. Rossi's estimate was only an educated guess. When combined with additional data from a third study, the witness broadened the range of this estimate to include zero, indicating that he could not predict with much certainty the proportion of the housewife population that regarded Wonder Bread as nutritionally superior. ${ }^{36}$

Such a line of cross-examination would not have been possible without an appreciation of the nature and procedure of the studies and sufficient disclosure by the party offering the evidence of the resulting data and statistical methodology used in analysis. While diligent and wearisome cross-examination might reveal this information, pretrial disclosure of information comparable to that specified in the FDA regulations might streamline the process. ${ }^{37}$

The Wonder Bread survey is similar to the clinical investigations described in the FDA rules in that it required the use of control groups. The effect of exposure to television advertisements on viewers' perceptions, like the effect of exposure to Red Dye No. 2 on bodily tissue, could be quantitatively compared for those who had been exposed and those who had not.

In some cases, the failure to retain the purity of the control group has resulted

33. 83 F.T.C. 865 (1973), modified, 532 F.2d 207 (2d Cir. 1976), order superseded, 90 F.T.C. 181 (1977).

34. Id. at $973-74$.

35. Id. at 907 .

36. Id.

37. The need for streamlining litigation in cases involving quantitative evidence is specifically recognized in the Data Committee Recommendations, supra note 6 , as being in the spirit of the general recommendation made in the MANUAL FOR COMPLEx LITIGATION (5th ed. 1982) that as many issues as possible relating to data and its analysis be resolved prior to trial. This need is also recognized generally in local rules encouraging settlement and in FED. R. Civ. P. 16 (Pre-trial Procedure; Formulating Issues), which give courts discretion to direct attorneys for the parties to confer in order to simplify issues and obtain admissions of fact and documents which will avoid unnecessary proof. The desirability of expanded pretrial discovery and some suggested rules are discussed later in this article. 
in complete rejection of the study. In Warner-Lambert Co., ${ }^{38}$ the famous Listerine case, potential observer awareness of which group was the control and which was actually gargling with Listerine led to a rejection of the results. ${ }^{39}$ This problem is referred to as a lack of "blindness" in a study.

The study was designed to examine the effectiveness of gargling with Listerine in preventing colds. School students gargled with either a colored water rinse or Listerine and were examined by a doctor when they contracted colds. Because the doctor could smell Listerine on the breath of any complaining student, the test was biased. Because the students could tell from the flavor whether they were gargling with Listerine or water, and because they might have been exposed to Listerine advertisements on television, this clinical investigation was not "accurate and wellcontrolled."

In evaluating the utility of the test, the Commission found that the test lacked probative value to "show that the use of Listerine is efficacious for colds and cold symptoms." 40 Under the FDA principles, this poorly controlled experiment might be useful only for purposes of corroboration. The FTC found that "the overwhelming weight of probative evidence" compelled a conclusion that Listerine was not efficacious in preventing colds. ${ }^{41}$

Although evidence from clinical studies is utilized in disputes under both the FDA and the FTC, the FDA principles cannot be translated wholesale into the FTC context. The legal issue towards which the FDA principles are directed is whether the manufacturer has "substantial evidence" in the form of an "accurate and well-controlled" clinical investigation. ${ }^{42}$ The FTC, in advertising cases, must decide whether the advertisements have a "tendency and capacity to mislead."4.3 Thus two additional considerations are involved in FTC determinations. One consideration is that the Commission must balance contradictory results from competing clinical investigations in evaluating the accuracy of product claims, rather than determine whether a manufacturer has one "adequate and well-controlled" study behind him to prove efficacy. ${ }^{44}$ The second consideration is that even literal truthfulness of the claim will not protect the advertiser if the resulting advertisement is deceptive. ${ }^{45}$

Moreover, not all quantitative propositions evaluated by the FTC in deceptive advertising cases can be characterized as testable by structured, controllable clinical investigations. Cases involving surveys, for instance, often involve the questioning of individuals who do have a specialized knowledge about the product manufactured or sold by defenders of advertising practices. This procedure can be contrasted to the questioning of a control group which is unfamiliar with the

38. Warner-Lambert Co., 86 F.T.C. 1398 (1975), modified, 562 F.2d 749 (D.C. Cir. 1977), cert. denied, 435 U.S. 950 (1978).

39. Id. at 1431-32.

40. Id. at 1428 .

41. Id. at $1496-97$.

42. 21 C.F.R. $\$ 314.111$ (a)(5) (ii)(a)-(c) (1983).

43. See Warner-Lambert Co., 86 F.T.C. at 1461 .

44. Id. This distinction is drawn by the Commission.

45. See, e.g., P. Lorillard Co. v. FTC, 186 F.2d 52 (4th Cir. 1950) (advertisement claim of "lowest tar and nicotine" among tested brands true but deceptive because actual difference in levels was negligible). 
product that is the subject of the inquiry. This is true both of cases investigating the legitimacy of an advertised survey, the results of which are allegedly deceptive, and of cases where a survey is offered as part of the evidence that an advertisement is deceptive.

In Litton Industries, Inc. ${ }^{46}$ which illustrates the first type of survey use, the manufacturer advertised that " $76 \%$ of the independent microwave oven service technicians surveyed recommend Litton." 47 The survey respondents were 234 technicians who worked for independent service agencies authorized to service Litton microwave ovens and who serviced at least one other microwave brand. ${ }^{48}$ The FTC charged that the survey, even though conducted by an independent testing agency, ${ }^{49}$ did not support this and related advertising claims.

The basic error was that the testing agency surveyed technicians who worked at Litton-authorized service agencies appearing on a list provided by Litton. The list was intended to include service technicians who were free of the biasing influence of a relationship to a manufacturer or a dealer. However, some of the dealers were included on this list of authorized service agents on their insistence as a precondition for their carrying Litton ovens. Litton knew, or should have known, ${ }^{50}$ that the lists were tainted by the inclusion of servicing dealers who, because they combined a sales and service function, might have a bias towards a particular oven.

It was concluded that because the survey was potentially biased in Litton's favor, the survey did not provide a reasonable basis for Litton's advertising claim. The problem in Litton was not an improper control group, although the Commission was presented with a quantitative comparison of the reactions of different human "subjects." The problem was one of partiality, more generally defined as nonrandomness, which is typically associated with surveys.

The problem of randomness also appears in Kroger Co. ${ }^{51}$ Although the case is considered by some to "set an unrealistic standard of methodological purity for advertisers using surveys, ${ }^{552}$ it provides an instructive example of a survey of nonhuman subjects.

Kroger, a retail food chain, advertised survey-based food price comparisons, known as the "Kroger Price Patrol," to support advertised statements such as "The Price Patrol Proves You Save More at Kroger" and "Shopping at Kroger will enable you to spend less for your food than at any other store." 53 The survey compared prices for 150 food items at Kroger and other retail food markets. Kroger advertised the results by relating how many items had higher prices at Kroger and how many items had higher prices at competitive stores. Not surprisingly, the results favored Kroger.

46. 97 F.T.C. 1 (1981)

47. Id. at 15 .

48. Id. at 16 .

49. Id. at 22-23.

50. Id. at $26-28$

51. 98 F.T.C. 639 (1981), modified. 100 F.T.C. 573 (1982).

52. 44 ANTITRLST \& TKADE Reg. REP. (BNA) No, 1097, at 56 (Jan. 13, 1983).

53. 98 F.T.C. at 641 . 
Two sources of nonrandomness entered into the survey process. The first was that the store employees knew, when changing prices, which items were included on the Price Patrol Survey. This knowledge enabled Kroger employees to prevent price increases and even to institute decreases on items on the survey. The proponent of the survey was effectively in control of the outcome. In addition, some significant categories of food items such as meat, produce, and certain dairy items were omitted from the Price Patrol survey. This meant that the survey did not sample a random selection of grocery items. This selection of categories combined with control over prices of the survey items theoretically allowed Kroger to have higher prices while its survey showed its lower prices.

The initial order of the FTC $^{54}$ required that Kroger refrain from advertising survey results or claims based on any surveys unless:

A. The survey is "designed and conducted" using methodologically sound procedures;

B. "Any results . . . which are advertised . . . [are] presented in a manner that fairly and impartially represents those conclusions . . .;"

C. "The results, data and complete description of the method . . . are . . . available to the public for inspection and copying . . .;"

D. The advertisement "clearly and conspicuously" discloses that the survey does not include any significant category of food unless that category is fairly and adequately represented in the survey. ${ }^{55}$ The emphasis is not only on prevention of deception in advertising, but also on public disclosure of both the results and the underlying methodology, reminiscent of the FDA requirement of disclosure of methodology necessary for outsider review and reanalysis.

In California Milk Producers Advisory Board, ${ }^{56}$ the Commission considered the results of a survey which demonstrated the viewing audience's interpretation of the advertisement, as in the Wonder Bread studies discussed above. Unlike the Wonder Bread study, which compared the product impressions of a group exposed to the advertisements with those of a group not exposed to the advertisements, there was no need for a control group in California Milk. The issue was not the effect of the advertisement on viewers' perception of the product but, rather, the viewers' perceptions of the message the commercials were attempting to convey. To find a group of people with the requisite special knowledge, the surveying advertising agency for the organization of milk producers telephoned over 9000 phone numbers to find 465 persons who had watched television advertisements conveying the message, "Every body needs milk." ${ }_{57}$ This process explicitly eliminated from consideration those subjects who would fit into a "control" group.

When considering survey evidence, the FTC may or may not benefit from the FDA guidelines for clinical studies, depending on whether or not the survey requires a control group. This is true both for surveys which are deceptively advertised and for surveys used to prove or disprove deception. The use of surveys

\footnotetext{
54. Id. at $717-21$.

55. Id. at 718-20; see also id. at 773-74.

56. 94 F.T.C. 429 (1979).

57. Id. at 460 .
} 
gives rise to additional problems, such as a randomness, which implicitly affect clinical investigations but are not explicitly addressed in the FDA principles. Those principles do suggest, however, considerations relevant to a set of FTC guidelines.

\section{III}

\section{Finkelstein Protocols Provide Model for Evaluation of ECONOMETRIC STUDIES}

\section{A. Protocols for the Use of Regression Models in Administrative Hearings}

The protocols described by Michael Finkelstein ${ }^{58}$ for application by administrative agencies lend themselves more directly to social science research than to the type of clinical investigation contemplated by the FDA principles. However, because the quantitative evidence considered by the FTC lies somewhere between those two models, a consideration of the protocols will be instructive. To systematize and simplify the use of statistical models:

1. [An administrative] decision maker should [(a)] specify the data of such relevance and importance that he finds merits econometric analysis, and [(b)] require that econometric presentations begin with those data and incorporate other data on a separate basis only when necessary for the purpose of accuracy or refinement. ${ }^{59}$

2. [A] party objecting to an econometric model introduced by another party should demonstrate the numerical significance of his objections whenever possible, and [(b)] a party objecting to a model . . . designated by the decision maker for econometric analysis should produce a superior alternative analysis of those data. ${ }^{60}$

3. [I]n any case in which the decision maker resorts to significant use of econometric findings, he should select the model that most usefully describes the data and . . . base his findings on that model. ${ }^{61}$

4. [A] finding resting in substantial part on data which have been analyzed econometrically should be no more precise than the finding which the decision maker is prepared to accept on the basis of econometric analysis. 62

A critical distinction between the FDA principles and these protocols is that the clinical investigations contemplated by the FDA are a method by which data are derived, whereas the protocols guide the analysis of quantitative evidence and subsequent litigation and decisionmaking.

Finkelstein finds support for his protocols in cases evaluating data describing the cost of equity capital for various regulated utility groups and the variability of their earnings, ${ }^{63}$ historical cash prices for wheat, ${ }^{64}$ historical prices for natural gas, ${ }^{65}$ cost and transaction data for brokerage firms, ${ }^{66}$ and airline fares and air

58. M. FinkELSTEIN, supra note 6 , at $232-47$

59. Id. at 232-33. It is contemplated that the decisionmaker will receive submissions from the parties on the appropriate data base and then designate the data he deems appropriate.

60. Id. at 238 .

61. Id. at 244 .

62. Id. at 247 .

63. Western Union Tel. Co., 34 F.C.C.2d 914 (1972), 51 F.C.C.2d 205 (1975), cited in M. FInKELSTEIN, supra note 6 , at 215.

64. Cargill, Inc., No. 120 (C.E.A. Aug. 13, 1970), affd, 452 F.2d 1154 (8th Cir. 1971), cert. denied, 406 U.S. 932 (1972), ciled in M. Finkelstein, supra note 6, at 224.

65. Permian Basin Area Rate Proceeding, 34 F.P.C. 159 (1965), affd, 390 U.S. 747 (1968), cited in M. Finkelstein, supro note 6, at 227-29; Southern Louisiana Area Rate Proceeding, 40 F.P.C. 530 (1968), 
traffic. ${ }^{67}$ In each of these cases, it was unnecessary for the appropriate agency to conduct an experiment, perform tests on individual subjects, or establish control groups. The data were already available for analysis.

However, collection of the data may present enormous problems. Recorded data are often scattered over many locations, although still available at some cost. In addition, analysis of the data is by no means simple. This type of case does require decisions as to which data to evaluate, for example, what variables are relevant, which measurements are appropriate, and which analytical model is most descriptive of the phenomenon being studied.

The litigation of claims based on clinical studies and claims based on econometric studies that analyze different data have a common element. Whether comparing scientific studies that have conflicting results or comparing econometric results that have different data bases, the decisionmaker is required to investigate several models of research in order to select the one that is most appropriate. This similarity ignores the differences in how the data is gathered and in the analytical process between reports of clinical investigations and alternative econometric models. Different clinical investigations require independently generated experimental data while alternative, conflicting econometric models may share the same raw numerical input.

Employment discrimination cases, which seem to capture the attention and interest of many scholars and practitioners interested in the use of quantitative evidence in litigation, are of the nonclinical type. It is not surprising that a different set of principles should direct the development and presentation of statistical evidence in these cases.

The Title VII case of Presseisen $v$. Swarthmore College ${ }^{68}$ provides an example of these econometric arguments. In Presseisen, a terminated assistant professor in the Education Program at Swarthmore alleged unlawful employment discrimination on the basis of sex in violation of the Equal Employment Opportunity Act of 1972.69

To support the claim that Swarthmore discriminated in setting salaries, the plaintiff's expert witness, Dr. deCani, testified that sex appeared to be a statistically significant factor in setting salaries. ${ }^{70}$ His testimony was based on a multiple regression analysis that he had performed on salaries for full-time faculty at Swarthmore using as independent variables sex, age, years since highest degree, years at Swarthmore, degree, and academic division.

The defendant's expert witness, Dr. Iverson, employed the same data base drawn from employment records at Swarthmore but used slightly different vari-

modified, 41 F.P.C. 301 (1969), affd, 428 F.2d 407 (5th Cir.), cert. denied, 400 U.S. 950 (1970), ciced in M. FinKELSTEIN, supra note 6, at 227-29.

66. SEC Rate Structure Investigation of National Securities Exchanges, No. 4-144 (S.E.C. filed May 28, 1968), cited in M. FINKELSTEIN, supra note 6, at 235.

67. Domestic Passenger Fare Investigation Phase 7, No. $21866-7$ (C.A.B. Apr. 9, 1971), 57 C.A.B. 188

(1971), 63 C.A.B. 291 (1973), cited in M. FinkELstein, supra note 6, at 240.

68. 442 F. Supp. 593 (E.D. Pa. 1977), affd, 582 F.2d 1275 (3d Cir. 1978).

69. 42 U.S.C. $\S \S 2000$ e to $2000 \mathrm{e}-17$ (1976 \& Supp. V 1981).

70. Presseisen, 442 F. Supp. at 614-15. 
ables in his regression model-rank, division, sex, years in a given rank, and degree. Dr. Iverson testified that the sex variable did not yield a statistically significant disparity. ${ }^{71}$

The purpose of these regression analyses was to separate and quantify the influences of the independent variables on salary. There is no suggestion that any computational error resulted in one expert finding that sex played a significant role in salary determination while the other found that it did not. The difference is in the model, that is, in the initial decision as to what variables affect the salary determination. Much was made in this case of the decision whether or not to include the variable "rank." While the court resolved this issue in favor of Dr. Iverson and the defendant, it essentially took an agnostic stance with respect to the models, suggesting the possibility "that the salary issue is inherently incapable of being analyzed through statistics," 72 and found no proof of discrimination. In contrast, FTC reviews of clinical studies are more likely to direct criticism against the method by which the data was derived than against how it was analyzed. ${ }^{73}$

Reports of similar econometric feuds in FTC cases filter down from expert witnesses hired to do battle. Dr. Peter Rossi relates a tale of three days on the witness stand defending his econometric models against the lawyers for American Home Products who sought to protect the image of Anacin in a deceptive advertising case. ${ }^{74}$ The chief lawyer for Anacin had taken an advanced course in multivariate analysis in preparation for the battle and was flanked by platoons of econometricians who "sent a steady flow of yellow slips of paper toward him" with questions to harass the enemy. ${ }^{75}$ Thus, cases before the FTC are likely to involve the fights over econometric modeling that characterize discrimination cases as well as an analytical similarity in litigation strategy.

\section{B. Coordinating Data Analysis Between Opposing Parties}

FTC cases generally involve clinical or survey evidence that has either been offered by the party whose commercial practice is challenged or been prepared by an expert for the Commission. Just as the evaluation of clinical studies benefits from incorporation of FDA principles, litigation involving data prepared for the purpose of a Commission hearing may benefit from protocols to be applied to business data and surveys made for the purpose of litigation. The similarities between administrative agency hearings and FTC decisionmaking suggest that it would be appropriate to take a closer look at the New York City Bar's Data Committee Recommendations, ${ }^{76}$ which are patterned after the Finkelstein protocols, for managing cases with substantial quantities of data.

Three relevant principles may be taken from these recommendations: (1) the

71. Id. at 616 .

72. Id. at 619 .

73. See, e.g., Warner-Lambert Co., 86 F.T.C. 1398 (1975), modified, 562 F.2d 749 (D.C. Cir. 1977), cert. denied, 435 U.S. 950 (1978)

74. M. Saks \& C. Baron, The Use, Nonuse, and Misuse of Applied Social Research in the COURTS 98 (1980).

75. Id. at 100 .

76. See Data Committee Recommendations, supra note 6. 
principle of cooperation, (2) the principle of pretrial settlement of issues, and (3) the principle of simplification. The recommendations incorporate the principle of cooperation by suggesting that, before trial, each party make available to the other parties machine-readable and hard copy documentation of the data used in its analysis, a list of its data evaluation personnel, and a report on its expert's data base, methods of analysis, assumptions, and conclusions. ${ }^{77}$ This recommendation to exchange data is more relevant to surveys developed for FTC hearings than to clinical studies which address the same ultimate issues of safety or efficacy using different data bases. Such cooperation not only limits the need for extended discovery while the expert is testifying on the stand during trial, but also furthers the principle of pretrial settlement by promoting a common understanding of each party's stance with respect to the merits of the case and by encouraging settlement of evidentiary issues peripheral to the ultimate legal or factual issues to be decided at trial.

Pretrial settlement is also encouraged by a recommendation that all objections to data or methods of analysis be raised prior to trial. ${ }^{78} \mathrm{~A}$ major difficulty with the evaluation of statistical evidence by a finder-of-fact, whether or not empirically oriented and statistically sophisticated, is that it is too late once an expert is on the stand for the expert to respond to challenges by hostile lawyers asking him to quantify the implications of objections raised by the opposing expert.

In the Presseisen case discussed above, ${ }^{79}$ an expert for the defendant criticized plaintiff's expert Dr. deCani's regression analysis for failing to measure the effect on salary of a teacher's ranking among the junior, as opposed to the senior, faculty. Since the challenge was not disclosed until the plaintiff was at trial, it was too late for Dr. deCani to incorporate the potentially negligible effect of this criticism into his model. As a result of this and similar unanswerable criticisms, his modeling was in vain. The principle of simplification would have been furthered had objections been made before the trial began. Justice would also be better served by an exchange of data prior to trial than by unexpected cross-examination of the experts on the stand.

In the administrative context there is greater opportunity for parties to coordinate modeling activity than in the judicial context. In a case before the Federal Energy Regulatory Commission (FERC), ${ }^{80}$ a state utilities commission challenged the choice of independent variables used by an expert relied upon by the FERC. The expert was given time to recalculate the critical coefficients; he estimated the difference between the original and modified findings to be only $3 \%$, which the court found on review to be an insignificant difference. ${ }^{81}$ Guidelines for FTC practice should recognize such opportunities for cooperative analysis.

The principle of simplification would also be served by the Committee's recom-

77. See id. Recommendations $1,2,5,6$, at 6-11, 19-21.

78. Id. Recommendation 8 , at 22 .

79. Presseisen v. Swathmore College, 442 F. Supp. 593 (E.D. Pa. 1977), affd, 582 F.2d 1275 (3d Cir. 1978).

80. South Dakota Pub. Util. Comm'n v. Federal Energy Regulatory Comm'n, 643 F.2d 504, rev'd, 668 F.2d 333 (8th Cir. 1981).

81. Id. at 512 . 
mendation that the effects of asserted defects in an opposing party's study be quantified whenever possible by the objecting party. ${ }^{82}$ Shifting the burden of quantification eliminates the need for a party to examine and quantify all objections raised by an opposing party. This procedure would simplify trial preparation, and help prevent valuable, informative evidence from being disparaged and ignored simply because the expert cannot recompute while on the stand. It would also simplify the task facing the finder-of-fact by providing an indication of the weightiness of an objection or the importance of a certain line of crossexamination.

A set of guidelines for the FTC and practitioners to follow in deceptive advertising cases might beneficially be drawn from an amalgamation of principles in the FDA regulations, Finkelstein's protocols for administrative decisionmakers, and the Data Committee Recommendations. The guidelines must ensure: (1) methodological soundness in choosing the data base to be analyzed whether it is a clinical test, a survey, or a sampling; (2) cooperation among parties in preparation for formal adjudicatory hearings in order to ensure the fullest possible examination of the relevant data; and (3) a constructive format for presenting evidence to the fact finder. In each of the three stages implicit in the guidelines, that is, data gathering and modeling, pretrial preparation and discovery, and litigation, the underlying organizational goal is to ensure that the evidence developed has the greatest possible practical, as well as statistical, significance.

\section{IV}

\section{Practical and Statistical Significance}

The evidence in the Warner-Lambert case that failed to establish the efficacy of Listerine in preventing colds was found to be lacking in probative value because the test was methodologically unsound, due to lack of blindness and lack of effective control, and because the results showed only negligible differences between gargling with Listerine and water. ${ }^{83}$ If a test is methodologically unsound, then the quantitative estimates produced, even if great in magnitude, are not relevant as evidence. Given this insubstantial foundation, the estimates do nothing to establish the truth or falsity of a factual assertion. Similarly, if a test is methodologically unsound, statistical tests designed to estimate the probability that a quantitative estimate could have occurred by chance are not useful because theoretical assumptions underlying those tests, such as randomness of a sample, are violated. Methodological soundness is an obvious predicate for the relevance of quantitative evidence, but it alone is not enough to ensure relevance.

Principles for determining which relevant quantitative evidence is noteworthy, or makes a material difference, and which relevant quantitative evidence is not due to chance, or is credible, are a necessary part of the guidelines to be designed to facilitate litigation. Practical and statistical significance are both terms of art.

82. Data Committee Recommendations, supra note 6 , at 20-21.

83. Warner-Lambert Co., 86 F.T.C. 1398, 1432 (1975), modified, 562 F.2d 749 (D.C. Cir. 1977), cert. denied, 435 U.S. 950 (1978). 
A measurement that is very unlikely to have occurred by chance is of great statistical significance. A measurement which is of great magnitude or is otherwise noteworthy is of great practical significance, as long as it is relevant to the legal or factual issues involved in a particular case. To be persuasive as evidence, quantitative conclusions based on methodologically sound studies must be both practically and statistically significant.

Standards for statistical significance accepted by social scientists, ${ }^{84}$ physical scientists, ${ }^{85}$ the Federal Trade Commission, ${ }^{86}$ and the Supreme Court, ${ }^{87}$ are confidence levels of $95 \%$ or $99 \%$, or equivalently, $5 \%$ or $1 \%$ significance levels, respectively. In Bristol-Myers, ${ }^{88}$ statistical techniques were used to evaluate the results of clinical investigations of the analgesic effect of various pain relievers. When the results of such studies purport to describe the differences between fungible drug products, it is important to know whether the asserted differences are due to chance, due to some random fluctuation, or due to an actual difference between the drugs.

A discussion of statistical significance includes the probability that differences calculated from the results of an adequate and well-controlled study could be due to chance. The significance level presents the probability between 0 , representing a zero probability that the difference is due to chance, and 1.00 , representing a $100 \%$ chance that the difference is due to random fluctuation in the observations made. Accordingly, the lower the significance, that is, the closer to zero, the greater the statistical significance. It is commonly accepted that a significance level of 0.05 , meaning that there is at most one chance in twenty that the difference is not real but is just due to chance, is a small enough probability of error that scientists can conclude that the differences are real. Naturally, an even lower significance level, such a 0.001 , would make a fact finder even more confident that there was a real difference. Evidence of a real difference resulting from a methodologically sound study is credible to a fact finder as long as the methodology and design of the study are clear and assumptions underlying the investigation are understood.

To be credible, the quantitative evidence must be statistically significant. Accordingly, much of the debate over statistical proof is over the statistical significance of the results. In the Listerine case, ${ }^{89}$ for instance, a test with over 3000 subjects at St. Barnabas Catholic School showed that there were statistically significant differences between the average severity on a 0 to 6 scale of colds and cold symptoms for students who gargled with Listerine and the control group who gar-

84. See, e.g., T. WONNACOTT \& R. WONNACOTT, INTRODUCTORY Statistics 173 (1969).

85. See, e.g., Bristol-Myers Co., No. 8917, slip op. at Findings 390-94, 425-28 (F.T.C. Sept. 28, 1979) (available on LEXIS, FTC library).

86. See, e.g., K Mart Enters., Inc., 84 F.T.C. 574, 575 (1974); Bristol-Myers Co., No. 8917, slip op. at 390-94, 425-28.

87. See Castaneda v. Partida, 430 U.S. 482,496 n.17 (1977) (applied two or three standard deviations rule equivalent to $95 \%$ to $99 \%$ confidence level).

88. Bristol-Myers Co., No. 8917 (F.T.C. Sept. 28, 1979) (available on LEXIS, FTC library).

89. Warner-Lambert Co., 86 F.T.C. 1398 (1975), modifed, 562 F.2d 749 (D.C. Cir. 1977), cert. denied, 435 U.S. 950 (1978); see supra text accompanying notes 33-37. 
gled with water. That data appeared as follows: ${ }^{90}$

\author{
Overall Severity \\ Symptom Severity \\ Nasal Discharge \\ Nasal Congestion \\ Postnasal Drip \\ Sneezing \\ Sore Throat \\ Cough
}

\begin{tabular}{cc}
$\begin{array}{c}\text { Listerine } \\
\text { Group }\end{array}$ & $\begin{array}{c}\text { Control } \\
\text { Group }\end{array}$ \\
\hline 2.191 & 2.305 \\
& \\
2.341 & 2.457 \\
2.657 & 2.787 \\
2.015 & 2.178 \\
1.811 & 1.946 \\
1.321 & 1.466 \\
1.920 & 2.112
\end{tabular}

Recorded and averaged over the four years of the study, these results were found by the clinical investigators to show statistically significant differences and thus to demonstrate that, for instance, the lower severity of coughing by those using Listerine, 1.920 compared to 2.112 , was not due to chance or some random fluctuation in the measurement.

The Commission notes, however, that "the existence of a statistically significant difference does not mean that the difference is medically significant or meaningful. There is a difference between statistical significance and medical significance." 91

The Commission is both right and wrong; it is correct in that one must consider the size of the difference to see whether it is of therapeutic importance. The statistical significance "does not indicate the size of the difference or how much benefit is to be expected because of the difference. If a large enough sample is used a very, very small difference can be found to be statistically significant."92

The Commission is incorrect in suggesting that a finding of statistical significance is not conceptually meaningful. The purpose of quantifying the results of a well-controlled clinical test is to examine alternative explanations for the difference, as in this case, between prevention of colds by gargling with water or with Listerine. The first explanation for the results which established a statistically significant difference is that Listerine performs as claimed by the manufacturer; the second explanation is that chance caused the disparity to occur. A statement that the difference is statistically significant represents a finding that chance is relatively unlikely (less than $5 \%$ probability) to have caused the difference. Given that the study was well-designed and executed so that alternative theories of causation are eliminated, the efficacy of Listerine is the only remaining causal factor.

The Commission's observation that increasing the sample size increases the probability of finding statistical significance does not disparage the study, but is merely an accurate comment on statistical methodology. Increasing sample size enables one to estimate the magnitude of any difference with greater precision. Even a small difference may be statistically significant in a large sample. A finding of statistical significance is meaningful in that it eliminates chance as a causal

\footnotetext{
90. Id. at 1432 .

91. Id. at $1432-33$.

92. Id. at 1432 .
} 
explanation, even though it gives no indication of the absolute magnitude of the demonstrated difference and, therefore, of its medical significance.

The first medical, rather than statistical, criticism of the results is that the differences are too small to convince the Commission that the difference has medical significance, or, as the concept is broadly denominated, practical significance. Remember that the cold victims were ranking severity of cold and cold symptoms on a scale of 1 to 6 with 6 representing greater severity. The reported results indicated that the difference between Listerine and the control group for coughing was only 0.192. The Commission, in discussing the medical significance of this result, correctly pointed out that one could not differentiate between a person suffering from a 1.920 degree cold and a 2.112 degree cold. ${ }^{93}$ It is safe to venture that a cold sufferer neither could nor would feel a 0.192 degree change in his or her condition.

Similar conclusions were reached in Stauffer Laboratories, Inc., ${ }^{94}$ the Magic Couch case. The seller of a motorized vibrating platform was ordered to cease advertising that the device helped to slim the body in particular areas such as hips, thighs, legs, and stomach, as well as to reduce overall body weight.

The manufacturer brought in a witness who claimed to have lost 130 pounds without changing her eating habits. ${ }^{95}$ In evidence presented to rebut the complaint, an expert measured the change in energy consumption as a result of using the machine; the difference appeared to be practically significant. Dr. Ellestad, the expert witness, reported a $10.5 \%$ increase in a body's energy usage while the machine was vibrating compared to when the machine was turned off.

Because this energy use translates into a 10.5 percent increase in calorie consumption, it would seem to make a significant difference in weight reduction. ${ }^{96}$ The results, however, were not statistically significant; the increase in energy consumption could have been due to random fluctuation in the variables observed. In this example, chance was not eliminated as a causal factor to explain why weight loss occurred. If the fact finder is not willing to believe the truthfulness of the asserted difference because there is too large a probability of error, then the evidence is not credible.

Evidence of statistical significance is found in cases other than those involving tests of medications, as in Listerine, or products, as in the Magic Couch case. For example, the cases using surveys are equally replete with findings of the presence or absence of statistically significant evidence.

In MacMillan, Inc. ${ }^{97}$ the Resource Planning Commission (RPC) was hired by the FTC to evaluate experiences of students who had been enrolled in courses run by LaSalle Extension University, a wholly-owned subsidiary of MacMillan, which

93. Id. at 1433 .

94. 64 F.T.C. 629 (1964), affd, 343 F.2d 75 (9th Cir. 1965).

95. Id. at 640 .

96. In the opinion of the Commission's expert, the results were not practically significant in addition to being not statistically significant. The increase in energy consumption translated into a burning of 8.5 calories per hour or $1 / 25 \mathrm{th}$ of an ounce of body weight. This amount of weight loss could also be achieved in six to eight minutes of sitting and talking. If the action of the vibrating couch alone were to be relied on for weight reduction, "it would take 400 days to lose one pound of weight." Id. at 642.

97. 96 F.T.C. 208 (1980) 
had been charged with misrepresenting job and earning potential for its graduates. To ensure that its survey of recent graduates was random and, therefore, unbiased, RPC compared characteristics of those who did respond to the survey to characteristics of those who did not. The opinion does not report the magnitude of any difference between these groups, but does indicate that "no statistically significant differences were found," leading to the conclusion that the respondents had not created a bias in the form of self-selection. 98 Since there was a greater than $5 \%$ probability that the difference occurred by chance, any assertion of a difference between respondents and nonrespondents was not credible and, consequently, the magnitude of any calculated differences did not matter.

The Bristol-Myers and Listerine cases suggest that quantitative evidence which is statistically significant but not practically significant will be unpersuasive. As illustrated in Magic Couch and MacMillan, any evidence that is not statistically significant will be unpersuasive, even if it is great in magnitude and would be of considerable practical significance were it not possible that the results were due to chance. As may be expected, evidence that is both statistically and practically significant will be credible and will carry considerable weight, while evidence that is neither statistically nor practically significant will not be worthy of belief and will carry no weight.

Material evidence is evidence that "makes a difference." Legal significance and "materiality" must be clearly distinguished from practical significance. In discussing the practical significance of results obtained from clinical studies, Dr. Beaver in Bristol-Myers said:

[T] he difference, to be a difference, must make a difference. What we would normally do is say if the difference is small beyond a certain point, it may, in fact, exist but it doesn't make any difference. It does not serve as a reasonable basis for choosing one product over another [or] making a particular claim about a product. ${ }^{99}$

From the FTC's perspective, a clinical finding that a difference is of no practical significance is material and, therefore, legally significant because the legal issue is whether there is a reasonable basis for the claim. A study showing no practically significant difference between the efficacy of different drugs is legally significant to the FTC claim because it fails to support the advertisers' claim. Thus, while neither the statistical significance nor the practical significance of quantitative evidence depends upon which party is considering it, the legal significance of the results does vary since it may support one party's allegations and defeat the other's. The results in the Listerine case were statistically significant but practically insignificant and, as such, lent weight only to the FTC's case because the differences shown were not large enough to demonstrate Listerine's efficacy.

98. Id. at 275 .

99. Bristol-Myers Co., No. 8917, slip op. at Finding 392 (F.T.C. Sept. 28, 1979) (available on LEXIS. FTC library). 


\section{Guidelines for Use of Quantitative Evidence in the Three STAGES OF FTC LITIGATION}

Guidelines for the use of quantitative evidence in FTC litigation can be based on the distinction between practical and statistical significance in the data preparation stage, the prehearing stage, and the litigation stage. The goals to be attained through these guidelines are simplification and prehearing settlement of evidentiary and legal issues, cooperation between parties, disclosure of relevant background materials, and clarification of substantive remedial requirements. Achievement of these goals will guarantee the integrity of fact-finding in deceptive advertising cases while intruding in the least restrictive manner on the free flow of commercial information.

Preparation of data for substantiation of advertising claims or of deception claims must be guided by sound methodologcal principles emphasizing the need for the opposing parties and fact finders to: (1) evaluate the design and method of data gathering and thereby establish the relevance of the results, (2) appreciate the practical import of the magnitude of the results, and (3) examine the statistical significance of the quantitative data. The Food and Drug Administration's principles for adequate and well-controlled clinical investigations might be interpreted as incorporating these three desiderata by requiring disclosure of objectives, methods, and controls and by requiring an evaluation of the data and a discussion of the statistical method employed. The FDA principles might serve as a model for proposed FTC guidelines for this type of clinical study, although the emphasis on evaluation of both practical and statistical significance should be made explicit. The manner in which the experimenter handled a variety of well-recognized factors, such as the establishment of a control group and subject and experimenter blindness, influences the extent to which fact finders will believe that the clinical results support the advertiser's claim. Clinical reports offered by any party might be justified in terms of the probative force of the empirical results and accompanied by a description of the legal significance of the results, assuming such results are found to be relevant and credible.

Just as there are well-recognized factors describing appropriate procedures in clinical studies, there are corresponding factors for surveys and econometric studies which are well-recognized in the social science literature. 100 The experimenter's inability to control social phenomena is the source of much error. The perceptions of a television viewer regarding the nutritional benefits of Wonder Bread have been affected by numerous forces external to the advertiser's control. These forces contaminate the conclusions of the surveyer just as awareness by a clinical subject or observer affects the blindness, and therefore the relevance, of a clinical investigation. Litigation guidelines might require that the direction of any bias resulting

100. Oskar Morgenstern observes that "at least all sources of error that occur in the natural sciences also occur in the social sciences: or, in other words, the statistical problems of the social scicnces cannot possibly be less serious than those of the natural sciences." O. MORGENSTERN, ON THE AC:CLR:NCY OF ECONOMIC OBSER VATIONS 7 (2d ed. 1963) 
from uncontrolled factors, and the associated legal significance, be explicitly identified in the report.

Survey data and data from the party's records frequently do not measure exactly the phenomenon in which the fact finder or researcher is interested; ${ }^{101}$ the investigator should note this failure. This problem may be compounded in a situation when business records are examined, such as the success rates of trade school graduates, because they are not made specifically for the purpose of trial or for the particular issue to be examined. The problem of imprecision may also arise when business records are created for the purpose of litigation due to the potential for falsification or misleading disclosure of information. In addition, survey data not taken from a party's records but generated for the party's own use, such as marketing studies made by a marketing agency for a client who is now before the Commission, ${ }^{102}$ might not directly address the ultimate issue before the court. Even if made for the purpose of the litigation, such data might suffer from a lack of randomness or other design defects associated with questionnaires. ${ }^{103}$

An explicit evaluation of the appropriateness and adequacy of study or survey design may be utilized not only in defense against deceptive advertising challenges by the FTC, but also in the context of a Commission order for substantiation which follows a finding of deception or, more commonly, a finding that no "reasonable basis" exists for the claims made. ${ }^{104}$ The need for disclosure and evaluation of methodology is barely implicit in FTC orders requiring substantiation of claims.

FTC orders to cease deceptive advertising are typified by an order issued to K Mart, which allegedly misrepresented the performance characteristics, construction, and structure of its tires. ${ }^{105} \mathrm{~K}$ Mart was ordered to cease and desist from:

making, directly or by implication, any statement or representation in any advertising or
sales promotional material as to the performance characteristics, construction or structure
of any automobile tire vended by respondent . . unless at the time of such statement or
representation respondent has a reasonable basis for such statement or representation,
which shall consist of competent scientific tests, or other objective material, and where such
statements or representation includes a comparison to other products, directly or by impli-
cation, such statement or representation shall be supported by competent scientific tests showing
not less than a ninety-five percent confidence level when subjected to appropriate statistical
analysis. ${ }^{106}$

The qualifications for competence of the scientific test are not set forth with as much particularity as required by the FDA principles or as suggested in this article as appropriate. While the Commission requires any demonstrated comparison to be statistically significant at a $95 \%$ confidence level, there is no requirement that a certain degree of practical significance support claims of product superiority. This practice ignores the case law indicating that negligible practical differences will

\footnotetext{
101. Id. at 14 .

102. See, e.g., California Milk Producers Advisory Bd., 94 F.T.C. 429 (1979)

103. See supra notes $86-87$ and accompanying text.

104. Pfizer, Inc., 81 F.T.C. 23, 65-74 (1972).

105. K Mart Enters., Inc., 84 F.T.C. 574,575 (1974)

106. Id. at 577 (emphasis added).
} 
not support an advertiser's claim as it might be deceptive even if true. ${ }^{107}$

On occasion, when fault has been found with a particular survey used in an advertising campaign, the Commission will indicate where the defect in scientific method lay and order the party to cease and desist from making representations concerning survey results unless the specific problem is corrected. Thus, in Litton, where the manufacturer's survey was tainted by the inclusion of potentially biased subjects, the order required Litton to cease and desist from:

\begin{abstract}
Advertising the results of a survey unless the respondents in such survey are a census or representative sample of the population referred to in the advertisement, directly or by implication. A representative sample need not be a probability sample so long as when the ad is first disseminated respondents have a reasonable basis to expect the sampling method used would not produce biased results. ${ }^{108}$
\end{abstract}

This is a step in the right direction in terms of specificity and clarity of requirements regarding the method of data gathering for quantitative evidence to be used in litigation.

The Commission's failure to specify the degree of proof necessary to show a material difference between products comparatively advertised, and indeed, the failure to note that a practically significant difference must be established at all, is a fault with such orders. No generally applicable standard exists to establish when practical differences are significant, although standards employed in clinical investigations may provide some guidance.

Clinical investigators use the property of sample size and statistical significance to help decide how big a difference is clinically, medically, therapeutically, or practically significant. Generally, as the sample size of a study increases, a small difference is increasingly likely to emerge as statistically significant. The Commission found in Bristol-Myers that "a meaningful way to resolve concerns over the magnitude of difference necessary for clinical importance is to require statistically significant differences to be obtained with a reasonable sample size and no greater."109 In the past, clinicians appeared to have been willing to find practical significance in tests of analgesics where statistical significance was found with twenty to fifty subjects, ${ }^{10}$ the theory being that if a clinically significant difference is going to show at all, it will show when using that number of subjects.

The clinicians' approach differs greatly from the approach in the Listerine case when experts merely asserted, though quite plausibly, that cold sufferers would not be able to notice an improvement in the severity of their coughs from 2.112 to 1.920.111 The difference, according to the experts' intuition, did not make a difference clinically.

In a variety of different fields where empirical investigations are made, investigators have developed and formalized their intuition as to what constitutes a practically significant difference. This is true for fields as diverse as the testing of a

107. See supra note 38 and accompanying text.

108. Litton Indus., Inc., 97 F.T.C. 1, 82 (1981).

109. Bristol-Myers Co., No. 8917, slip op. at Finding 393 (F.T.C. Sept. 28, 1979) (available on LEXIS, FTC library).

$110 . \mathrm{ld}$.

111. See supra text accompanying note 82 . 
variety of drugs pursuant to the FDA standards for adequate and well-controlled studies $^{112}$ and the evaluation of the job-relatedness of written examinations in employment discrimination cases. ${ }^{113}$ The fact finders in these cases rely to varying degrees on the expertise of empiricists familiar with the field.

In the preparation and presentation of quantitative evidence, it seems reasonable to expect that a complete report will discuss the degree of difference required to establish practical significance. Certainly, researchers should decide on a required degree of practical significance before seeing the results, just as they decide on a level of statistical significance beforehand. An order from the FTC to a party accused of deceptive advertising or of having no reasonable basis for a claim would be correspondingly more useful and clearer to the extent that it specified such a level of practical significance. Such specificity in orders as well as in guidelines would help prevent arbitrary and capricious action by the Commission.

The comments to the Data Committee Recommendations ${ }^{114}$ argue for pretrial cooperation and disclosure of information. The purpose underlying the recommendation that each party make available to the other documentation of the data used in its analysis and a report of its expert's data base, method of analysis, assumptions and conclusions is the same as the purpose served by full revelation of information in the FDA principles. Without full disclosure of basic data and assumptions, the process of investigating the meaning of quantitative results is impeded.

To lawyers, the act of disclosing their objections to data and its analysis is an awkward one because it necessitates revealing one's strategy to one's opponent before the battle. The Data Committee Recommendations are also sensitive to this potential objection. ${ }^{115}$ It may be that the adversary model is not well suited to the full development of quantitative evidence. The FTC's hearing process departs significantly from usual court proceedings in that the commissioners and their counsel are independent fact finders empowered to investigate beyond the evidence presented by conflicting parties. Hence, the hearing process may more readily incorporate the Data Committee's recommendations.

A pretrial disclosure rule might be guided by the distinctions between irrelevance due to poor methodological design, practical significance, and statistical significance. Issues related to the statistical significance of results should certainly be resolved prior to trial since disagreements between the parties are more likely to rest on differences in the data, erroneous calculations, or on techniques of statistical analysis than on strategic considerations. On the other hand, given that all parties are aware of the design and methodology of the underlying study, a lawyer might reasonably balk at revealing his or her list of design defects which tend to make the results appear irrelevant. Conflicting views of what constitutes a material difference might be resolved during litigation, but identification of the degree

112. Bristol-Myers Co., No. 8917, slip op. at Finding 395.

113. See, e.g., Boston Chapter, NAACP, Inc. v. Beecher, 371 F. Supp. 507 (D. Mass. 1974), affd, 504

F.2d 1017 (Ist Cir. 1974), cert. denied, 421 U.S. 910 (1975).

114. See Data Committee Recommendations, supra note 6.

115. Id. 
of difference might be an appropriate subject for pretrial agreement and stipulation.

In sum, the thesis here is that structuring debate over disclosure along the lines of relevance, practical significance, and statistical significance may be fruitful in the resolution of deceptive advertising cases. The fact finder will benefit from organizing the quantitative evidence along these lines in order to simplify and structure the statistical analysis, clarify the resolution of factual issues addressed by quantitative evidence, and clarify substantive remedial requirements through more specific orders to advertisers. 
